\title{
Youth mental health after civil war: the importance of daily stressors
}

\author{
Elizabeth A. Newnham, Rebecca M. Pearson, Alan Stein and Theresa S. Betancourt
}

\section{Background}

Recent evidence suggests that post-conflict stressors in addition to war trauma play an important role in the development of psychopathology.

\section{Aims}

To investigate whether daily stressors mediate the association between war exposure and symptoms of posttraumatic stress and depression among war-affected youth.

\section{Method}

Standardised assessments were conducted with 363 Sierra Leonean youth $(26.7 \%$ female, mean age 20.9 , s.d. $=3.38)$ 6 years post-war.

\section{Results}

The extent of war exposures was significantly associated with post-traumatic stress symptoms $(P<0.05)$ and a significant proportion was explained by indirect pathways through daily stressors $(0.089,95 \% \mathrm{Cl} 0.04-0.138, P<0.001)$.
In contrast, there was little evidence for an association from war exposure to depression scores $(P=0.127)$; rather any association was explained via indirect pathways through daily stressors $(0.103,95 \% \mathrm{Cl} 0.048-0.158, P<0.001)$

\section{Conclusions}

Among war-affected youth, the association between war exposure and psychological distress was largely mediated by daily stressors, which have potential for modification with evidence-based intervention.

\section{Declaration of interest \\ None.}

\section{Copyright and usage}

(c) The Royal College of Psychiatrists 2015. This is an open access article distributed under the terms of the creative commons Attribution (CC BY) licence.
Millions of children live in nations affected by war, ${ }^{1}$ and yet the resources available to ensure their safety, health and psychological recovery from trauma are severely limited. It is well established that children exposed to war are vulnerable to increased rates of post-traumatic stress disorder (PTSD), depression, anxiety and externalising behaviours (i.e. hostility and conduct difficulties) as measured via structured clinical interviews and standardised questionnaires. $^{2-4}$ Recent findings suggest a differential impact of war trauma on psychological disorder by gender. ${ }^{5-7}$ However, the specific intermediate factors through which adversity exerts its effects on psychological health have not been well defined. ${ }^{8}$ Recent investigations have questioned the hypothesis that distress arises solely from war experiences, and are shifting the focus towards the important role that the post-conflict environment plays in mediating psychological adjustment. ${ }^{9,10}$ Daily stressors, the social and material challenges caused or worsened by political instability and poverty, have traditionally been neglected in assessments of psychological outcomes among war-affected populations. An examination of the specific mediating role (the proportion of associations that are explained by indirect pathways) of daily stressors may inform the development and implementation of interventions that have potential to improve a range of modifiable factors in the post-conflict setting. The current study therefore aimed to investigate, first, the degree to which trauma exposure is associated with post-traumatic stress and depression among war-affected youth 6 years following the Sierra Leonean civil war. Second, we aimed to determine the extent to which daily stressors mediate the association between war exposure and symptoms of post-traumatic stress and depression. Building on prior literature investigating mental health outcomes among war-affected youth, ${ }^{9,11-13}$ it was hypothesised that war trauma would be more closely associated with symptoms of post-traumatic stress than depression. Further, we predicted that in both cases, the relationship between war exposure and psychological outcomes would be mediated by daily stressors.

\section{Method}

\section{Participants and study setting}

Participants were drawn from a longitudinal cohort study of waraffected youth in Sierra Leone conducted in collaboration with the International Rescue Committee. Children (male and female, $n=529)$ were interviewed at three time points (2002, 2004 and 2008) following the cessation of conflict. All participants were between 10 and 17 years old at baseline interview. The sample comprised three cohorts: former child soldiers who received non-governmental services for disarmament, demobilisation and reintegration (DDR) following the civil war $(n=264)$, former child soldiers who did not receive DDR services $(n=128)$ and a community sample of war-affected youth $(n=137)$.

In 2008,387 youth (comprising $73 \%$ of the full sample) were traced and interviewed. The current sample comprised youth interviewed at Time 3 who reported at least one war exposure $(n=363)$. Data for all participants were collected through individual interviews conducted in Krio, the lingua franca, by Sierra Leonean research assistants trained by the study principal investigators. All participants provided verbal informed consent in Krio, and consent and assent procedures were used where participants were younger than 18 years. As a token of appreciation, all participants were provided a small household item and refreshments (given at the end of the interview to avoid possible effects of coercion). Local social workers provided followup and referral for any participants who reported potential risk of harm or suicidality (approximately $5 \%$ of the original sample). Ethics approval was granted by the Institutional Review Board of the Harvard School of Public Health and the study was conducted in concordance with the Declaration of Helsinki.

\section{Measures}

The assessment battery comprised standardised measures forwardand back-translated from English to Sierra Leonean Krio, 
consistent with a standardised protocol. ${ }^{14}$ Cultural adaptation of items was conducted in consultation with Sierra Leonean staff and community members ${ }^{15}$ and the survey instrument was refined at each wave of data collection. War exposures were assessed at waves 1, 2 and 3, depression and post-traumatic stress symptoms at wave 2 and 3 , and daily stressors at wave 3 .

\section{War exposure}

The Childhood War Trauma Questionnaire ${ }^{16}$ was adapted to capture the exposures relevant to young people in Sierra Leone. The resulting 55 items were dichotomously coded (yes/no). Items covered violence witnessed, experienced and perpetrated by the participant, as well as bereavement and deprivation experienced during war. We used a total score, summing all war exposures, as we deemed the cumulative effects of war exposure most appropriate to the current analysis. This approach is consistent with prior research examining the effects of war and daily adversity, ${ }^{9,11,12}$ enabling comparison across studies.

\section{Daily stressors}

An adapted Post-War Adversities Index ${ }^{17}$ was administered to assess current hardship and difficulties. The 30 items examine issues related to housing insecurity, interpersonal adversities, food and economic security and neglect. Items include 'during the past 6 months, have you (your family) been evicted from your home, or forced to move into worse accommodations than you previously had?' and 'during the past 6 months, have people you live with had serious conflicts with each other (arguing, shouting, screaming)'. Items were scored dichotomously (yes or no ratings in response to their occurrence) and a summed total score was used in analyses. The scale has shown strong psychometric properties in prior studies. ${ }^{13}$

\section{Post-traumatic stress reactions}

A reduced version of the UCLA Post-Traumatic Stress Disorder Reaction Index (PTSD-RI) ${ }^{18}$ comprising the nine-item short form plus three items from the original long-form deemed most appropriate to the current setting was used to assess symptoms. Frequency of symptoms experienced in the past 4 weeks was reported on a three-point Likert scale (never, sometimes, often) with higher scores corresponding to higher levels of distress. Continuous scores were used. The PTSD-RI has demonstrated strong psychometric properties in prior studies of war-exposed youth, in a variety of settings including Sierra Leone. ${ }^{2,19}$ The 12-item scale had high internal consistency in this sample (Cronbach's $\alpha=0.84$ ).

\section{Depression symptoms}

The depression subscale of the Hopkins Symptom Checklist $\left(\right.$ HSCL-25) ${ }^{20}$ was used to assess depression symptoms. Items are rated on a four-point scale (not at all, a little, quite a bit, extremely) and continuous scores were used. The scale has been used to examine depression and anxiety in a number of war- affected samples with strong psychometric properties. ${ }^{20,21}$ Internal consistency in the current sample was strong (Cronbach's $\alpha=0.769$ ).

\section{Demographic characteristics}

Participants' age, gender, education and family socioeconomic resources were assessed using a demographic inventory administered with the interview. The inventory draws from items on the UNICEF Multiple Cluster Indicator Survey ${ }^{22}$ used previously in Sierra Leone.

\section{Statistical analysis}

For continuous variables, means and standard deviations were calculated, and for categorical data, descriptive statistics were calculated using frequencies. Independent sample $t$-tests were conducted to determine differences between genders. Correlations and descriptive analyses were conducted in IBM SPSS version 20.0 for Windows.

To investigate whether daily stressors mediated any association between war exposure and mental health outcomes, path analyses were developed. We modelled the associations in separate and then combined models, where correlations between each mental health outcome were taken into account. In the final model, all associations were mutually adjusted for each other and path coefficients represent 'independent' associations. Standardised path coefficients and standard errors were estimated using bootstrapping (5000 models) in MPlus for Windows. As all scores were continuous, a maximum likelihood estimator was used.

\section{Results}

\section{Sample characteristics}

The analytical sample comprised 363 youth (26.7\% female, mean age 20.9 years, s.d. $=3.38$ ) (Table 1$)$. More than half were currently in school $(n=205,56.5 \%)$ and $63.4 \%$ had completed grade 7 . Most participants $(n=295,81.3 \%)$ were living with a relative and $132(36.4 \%)$ lived with at least one parent at the time of interview.

\section{War exposures and outcomes by gender}

War exposures are outlined in online Table DS1. All participants had been exposed to war, and the average number of exposures

\begin{tabular}{|c|c|c|c|c|c|c|c|c|c|}
\hline & \multirow[b]{2}{*}{$n$} & \multirow[b]{2}{*}{ Mean (s.d.) } & \multirow[b]{2}{*}{ Range } & \multicolumn{6}{|c|}{ Correlations } \\
\hline & & & & Gender & Age & War exposures & Daily stressors & PTSD & Depression \\
\hline Gender, female & 97 & & & 1 & & & & & \\
\hline Age & & $20.87(3.38)$ & $13-24$ & -0.101 & 1 & & & & \\
\hline War exposures & & $14.91(7.50)$ & $1-34$ & 0.082 & $0.159 * *$ & 1 & & & \\
\hline Daily stressors & & $8.31(5.07)$ & $0-23$ & 0.005 & $0.160 * *$ & $0.198 * *$ & 1 & & \\
\hline PTSD & & $11.22(7.24)$ & $0-30$ & 0.080 & -0.046 & $0.116^{*}$ & $0.439 * *$ & 1 & \\
\hline Depression & & $29.9(7.34)$ & $16-49$ & 0.063 & 0.072 & 0.079 & $0.511^{* *}$ & $0.542 * *$ & 1 \\
\hline
\end{tabular}


was high (mean 14.9, s.d. $=7.5)$. Abduction into armed forces occurred as young as 2 years of age (mean 10.35 years, s.d. $=2.89$ ) and time spent in the fighting forces averaged 2.86 years $($ s.d. $=2.82)$. Females reported higher rates of experiencing rape than males in the sample, although sexual assault and exposure to rape was reported by both genders. No significant differences existed by gender for any other war exposure. Participants reported an average of eight daily stressors (s.d. $=5.07)$. The most commonly reported stressors were having experienced the death of someone close to the participant in the past year (78.2\%), lacking money for basic necessities (54.5\%), unemployment of the household's main wage earner (49.6\%), personal illness $(48.2 \%)$ and a member of the household experiencing depression (44.6\%). There were no significant differences by gender in reports of post-traumatic stress symptoms $(t(1,361)=-1.12, \quad P=0.263)$ or depression scores $(t(1,360)=-1.19, P=0.233)$.

\section{Associations between war exposures, post-war context and mental health}

There was evidence that war exposure and daily stressors were significantly associated with post-traumatic stress symptoms, as outlined in Table 1. There was no evidence for an association between the extent of war exposures and depression, although an association between daily stressors and depression was observed. Post-traumatic stress and depression symptoms were correlated to a moderate degree. Daily stressors and war exposure were moderately correlated, suggesting that they are related but to some extent independent.

\section{Mediation models}

Direct and indirect pathways from war exposure to post-traumatic stress symptoms and depression were calculated in separate and combined mediation models. The combined model was consistent with the models calculated for each mental health outcome, and is illustrated in Fig. 1. The total association (combination of all direct and indirect paths) from war exposure score to PTSD score was $0.112(95 \%$ CI $0.014-0.21, P<0.05)$. Of this total, there was evidence that a significant proportion, 0.089 (95\% CI $0.04-$ $0.138, P<0.001)$ was explained by indirect pathways through daily stressors. Thus, $79 \%$ of the association between war exposure and post-traumatic stress was mediated by daily stressors in the postconflict setting and once daily stressors were accounted for there was no longer evidence for an association between war exposure and PTSD. The total association (combination of all direct and indirect paths) from war exposure score to depression score was 0.083 ( $95 \%$ CI -0.023 to $0.189, P=0.127$ ). This association and further variance was accounted for by indirect pathways through daily stressors: 0.103 (95\% CI $0.048-0.158, P<0.001)$. Thus, the association between war exposure and depression symptoms was entirely explained by daily stressors, which helps to explain why the indirect pathway association was greater than the total association.

\section{Discussion}

\section{Main findings}

Six years following war, the high number of war exposures reported by Sierra Leonean youth was significantly associated with symptoms of post-traumatic stress, but not depression. The pathway from war exposure to psychological distress was largely mediated by current daily stressors for post-traumatic stress symptoms, and for depression there was only evidence for a pathway from daily stressors with no impact of war exposure alone. Effects were tested in both individual and combined models that examined the respective impact of trauma and daily stressors on both PTSD and depression symptoms. In all models the mediating role of daily stressors remained strong. Overall, the large effects of daily stressors suggest that despite exposure to severe and chronic violence during childhood, economic and interpersonal stressors experienced in the post-conflict setting appear to play a substantial role in young people's psychological impairment.

\section{Daily stressors in post-conflict settings}

In recent decades, wars have exerted a disproportionate burden on low- and middle-income countries. ${ }^{23}$ These nations have significantly fewer resources available to revive the health, education, legal and logistical systems necessary to support post-conflict recovery. As such, government and non-governmental agencies must make difficult decisions to direct the few resources available to programmes that will provide the greatest benefit in recovery and rebuilding after conflict. ${ }^{24}$ The current findings

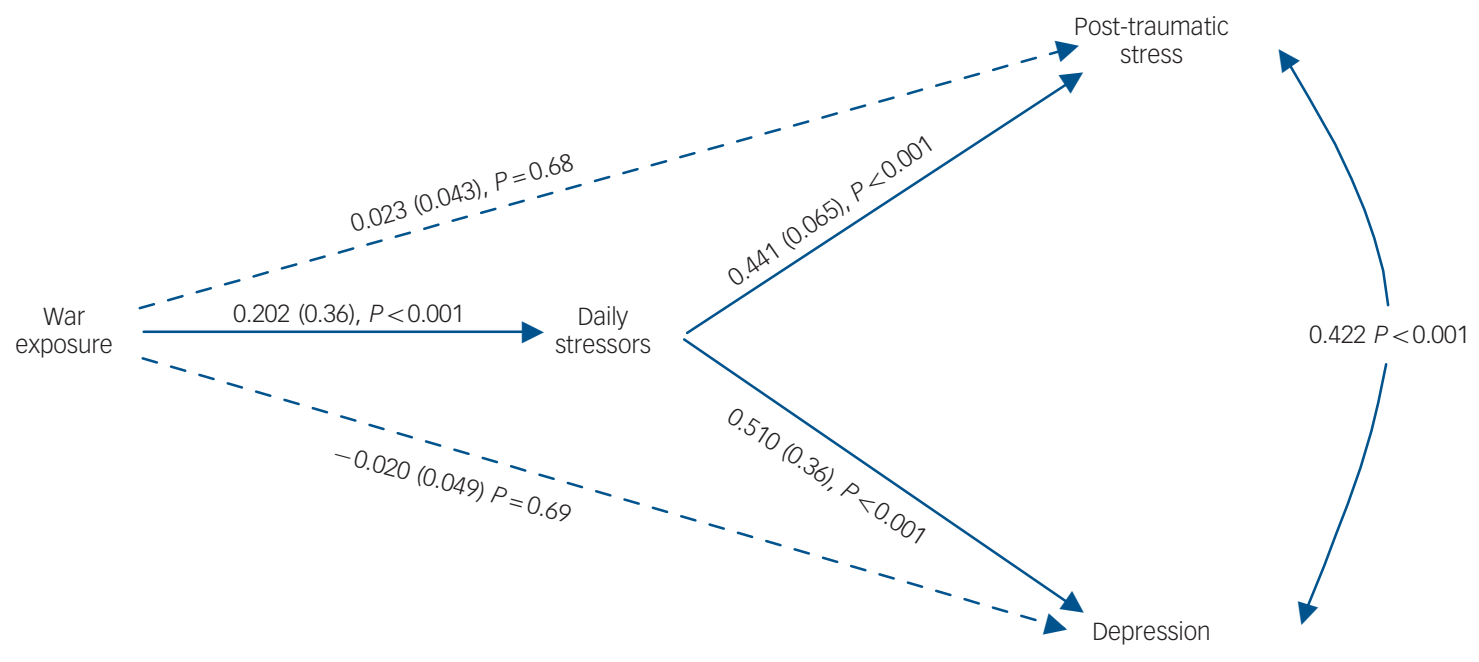

Fig. 1 Path model for war exposure, daily stressors and mental health outcomes among war-affected youth in a post-conflict setting. 
support a growing evidence base on the importance of daily stressors. For example, among adult Darfuri refugees living in camps in Chad, levels of distress were more closely correlated with basic needs and concerns about safety than with war traumas. ${ }^{25}$ Although many of the daily stressors arose from the experience of war, most salient to the participants were the impact of ongoing needs and hardships. Similar findings for Afghan, ${ }^{26,27}$ Bosnian, ${ }^{28}$ Iraqi and Bhutanese refugee adults ${ }^{11}$ have been documented, where a range of daily hardships and current stressors were significantly associated with poorer mental health outcomes in situations of ongoing instability. In studies of war-affected adults, variations in gender effects exist. Some studies have reported higher rates of stress among males ${ }^{29}$ and others in females, ${ }^{11}$ perhaps reflecting perceptions of belonging, achievement and contribution to the household, as well as the burden of responsibility. In contrast, there were no significant differences in post-traumatic stress reactions or depression symptoms in the current sample.

Among children and adolescents in adverse settings, a combination of traumatic events and daily stressors have been associated with internalising and externalising symptoms. ${ }^{9,12} \mathrm{~A}$ study of Sinhalese, Tamil and Muslim students who had experienced trauma related to war and/or the 2004 tsunami in Sri Lanka demonstrated that despite the dual burden of war and disaster, daily stressors of material deprivation, abuse and interparental conflict convincingly mediated the relationship between trauma exposure and PTSD. ${ }^{9}$ Similarly, internally displaced Eastern Congolese adolescents reported a significantly higher rate of traumatic exposure, higher vulnerability to insecurity and more daily stressors than adolescents who had returned home or those in a non-displaced cohort. ${ }^{12}$ Interestingly, those who had returned home did not differ significantly on daily stressors from the non-displaced group, suggesting that displacement and ongoing insecurity were particularly influential. Mels and colleagues ${ }^{12}$ found a stronger association between traumatic events, in combination with daily stressors, and posttraumatic stress reactions and internalising symptoms than that reported in the current study, perhaps because of higher levels of ongoing insecurity in the displaced cohort.

The current findings complement an established evidence base highlighting the important role of resettlement stressors on psychological outcomes among refugee children and adolescents in high-income nations. ${ }^{30}$ It is well recognised that vulnerability to hardship, isolation and adversity together with barriers to inclusion at school and community settings (including language barriers, cultural attitudes and stigma) place refugee-origin children and youth at risk of psychological difficulties. ${ }^{31}$ Socioeconomic circumstances, family health and cohesion, community integration and access to education following resettlement are important predictors of psychological adjustment among children resettled in both high- and low-income countries. ${ }^{3,30,32}$ Building on our understanding of the challenges facing children who are displaced or affected by disaster, the current study extends a more sophisticated picture of mental health for populations that remain in the post-conflict environment.

\section{Possible targets for intervention}

Wars destroy the societal infrastructure crucial to recovery. Health, education, food and water security, legal and protection systems are often damaged in prolonged conflicts, and this has significant implications for survivors. Youth in the current sample reported a high number of stressors 6 years following war, including economic, family and community stressors. Although common to post-conflict settings, these risk factors have the benefit of being potentially modifiable, and are increasingly the target of recovery and rehabilitation efforts. ${ }^{24}$ Ensuring child protection, increasing security in camps and improving access to medical care and education are already key targets of humanitarian programming, ${ }^{33}$ yet the current findings suggest that more could be done to address the long-term impact of war on young people's structural and interpersonal environments. Economic opportunity relates strongly to depression in both high- and low-resource settings. ${ }^{8,34}$ For youth returning from war, a lack of opportunities in educational and vocational sectors is a significant challenge, especially for females whose prospects are particularly poor. ${ }^{24}$ It is important that interventions for youth reporting distress in the post-conflict setting address psychological symptoms in the context of poverty, insecurity and interpersonal stability. ${ }^{35}$ Thus, psychological programmes that link with educational, vocational and industry partners may enable greater gains for youth seeking intervention after war. ${ }^{35}$

Similarly, social support and interpersonal relationships are wellestablished protective factors for depression and post-traumatic stress disorder. ${ }^{2,13}$ For children affected by war, including those who were actively involved in the violence, safe and reliable caregiver relationships are vital to psychosocial recovery. ${ }^{32}$ Many children face family loss and disintegration in the aftermath of war, and some return to situations of domestic violence, child abuse and neglect. ${ }^{36}$ Sadly, a landscape of loss often cultivates ongoing hardship. For those who were able to return to caregivers, the burden of illness and disability among family members may have increased stress and reduced opportunities to access school and work. Given the relative emphasis on the quality and wellbeing of caregivers in the Post-War Adversities Index used in the current study, this provides some indication of possible intervention targets. Further exploration of the child's interaction with their social ecology through adolescence and early adulthood will inform future modes of intervention.

\section{Limitations}

Several limitations should be considered. First, although efforts were made to sample from multiple districts in Sierra Leone and across former child soldier and community populations; the sample comprised youth who were all exposed to a particularly brutal and prolonged civil war, and the purposive recruitment methods mean that care should be taken in generalising to other populations. Second, self-reported measures of psychological symptoms were used. We have made substantial efforts to reliably translate, culturally adapt and pilot all measures; however the lack of psychiatric diagnostic assessment available in Sierra Leone means that the symptom scores do not reflect valid diagnoses. Third, self-reported psychological symptoms and stressors may be vulnerable to reporting bias, yet the stressor events covered by the Post-War Adversities Index are largely objective, and the bias in retrospective reports linked to psychopathology is likely to be minimal. ${ }^{37}$ Fourth, the model was built with cross-sectional data and thus it is difficult to determine the directional nature of the pathways. It is possible that mental health difficulties play a role in generating hardships and ongoing stressors. Yet, the importance of these stressors for mental health, particularly depression, suggests that irrespective of war exposure, daily hardships contribute to mental health problems. Longitudinal research is required to examine the directional nature of the relationship between daily stressors and psychological symptoms among youth living in post-conflict settings. It will also be important to determine the most potent stressors and clusters of adversities that will inform psychotherapeutic treatment mechanisms and broader public health interventions. 


\section{Implications}

Severe daily stressors in the post-conflict environment were found to mediate the relationship between the extent of war exposure and psychological difficulties among youth in Sierra Leone. These findings suggest potential avenues for intervention. Children and adolescents affected by war are not reacting solely to traumatic exposure; rather, it appears that their engagement with economic opportunities and healthy interpersonal relationships in the aftermath of war are vital to their psychological recovery. Although a small number of interventions for war-affected children have demonstrated effectiveness, ${ }^{38,39}$ a large number of treatments are implemented in the absence of empirical support. ${ }^{40}$ The model illustrated in Fig. 1 builds on an existing literature that draws attention to the proximal environmental context crucial to recovery, ${ }^{9,10}$ and has significant implications for clinical and public health interventions. Despite ongoing debate regarding the timing and focus of psychological interventions in postconflict settings, ${ }^{10,33}$ it is clear that 6 years on from war, daily stressors are a critical factor in adolescent and youth health. Clinical programmes implemented in post-conflict settings have significant opportunity to address these modifiable factors, and should work to integrate with educational, vocational and social support programmes. Opportunities to engage with families and communities to embrace stability and healthy functioning, in addition to trauma-focused care, are vital for sustainable improvement. Expanding treatment approaches by incorporating a focus on daily stressors therefore reflects an important shift in addressing the needs of youth in post-conflict settings.

\footnotetext{
Elizabeth A. Newnham, MPsych(Clin), PhD, François Xavier Bagnoud Center for Health and Human Rights, Harvard School of Public Health, Boston, USA and School of Psychology, The University of Western Australia, Perth, Australia; Rebecca M. Pearson, PhD, School of Social and Community Medicine, Bristol University, Bristol UK; Alan Stein, MB, BCh, MA, FRCPsych, Department of Psychiatry, University of UK; Alan Stein, MB, BCh, MA, FRCPsych, Department of Psychiatry, University of
Oxford, Oxford, UK; Theresa S. Betancourt, MA, SCD, François Xavier Bagnoud Center for Health and Human Rights and Department of Global Health and Population, Harvard School of Public Health, Boston, USA

Correspondence: Elizabeth A. Newnham, School of Psychology, The University of Western Australia, 35 Stirling Highway, Crawley, 6009, Western Australia, Australia. Email: Enewnham@hsph.harvard.edu

First received 12 Feb 2014, final revision 19 Jun 2014, accepted 25 Jul 2014
}

\section{Funding}

E.A.N. was supported by an Early Career Fellowship from the National Health and Medical Research Council of Australia. R.M.P. was supported by an Early Career Fellowship funded by a Wellcome Trust Institutional Award (097822/Z/11/ZR).

\section{Acknowledgements}

We wish to thank our research assistants and coordinators in Sierra Leone, and colleagues at the International Rescue Committee for their collaboration in this work. We are most grateful to the participants and their families who have donated their time and thoughts, and enhanced our understanding of mental health and resilience in the post-conflict environment.

\section{References}

1 UNICEF. Humanitarian Action for Children 2013. UNICEF, 2013.

2 Betancourt TS, Newnham EA, McBain R, Brennan RT. Post-traumatic stress symptoms among former child soldiers in Sierra Leone: follow-up study. Br J Psychiatry. 2013; 203: 196-202.

3 Reed RV, Fazel $M$, Jones $L$, Panter-Brick $C$, Stein A. Mental health of displaced and refugee children resettled in low-income and middle-income countries: risk and protective factors. Lancet. 2012; 379: 250-65.

4 Okello J, Nakimuli-Mpungu E, Musisi S, Broekaert E, Derluyn I. War-related trauma exposure and multiple risk behaviors among school-going adolescents in Northern Uganda: the mediating role of depression symptoms. J Affect Disorders 2013; 151: 715-21.
5 Annan J, Blattman C, Mazurana D, Carlson K. Civil war, reintegration, and gender in Northern Uganda. J Conflict Resolut 2011; 55: 877-908.

6 Armour C, Elhai JD, Layne CM, Shevlin M, Durakoviæ-Belko E, Djapo N, et al Gender differences in the factor structure of posttraumatic stress disorder symptoms in war-exposed adolescents. J Anxiety Disord 2011; 25: 604-11.

7 Betancourt TS, Borisova II, De la Soudiere M, Williamson J. Sierra Leone's child soldiers: war exposures and mental health problems by gender. J Adolesc Health 2011; 49: 21-8.

8 Brent $D$, Silverstein $M$. Shedding light on the long shadow of childhood adversity. JAMA 2013; 309: 1777-8.

9 Fernando GA, Miller KE, Berger DE. Growing pains: the impact of disaster related and daily stressors on the psychological and psychosocial functioning of youth in Sri Lanka. Child Dev 2010; 81: 1192-210.

10 Miller KE, Rasmussen A. War exposure, daily stressors, and mental health in conflict and post-conflict settings: bridging the divide between traumafocused and psychosocial frameworks. Soc Sci Med 2010; 70: 7-16.

11 Jordans M, Semrau M, Thornicroft G, van Ommeren M. Role of current perceived needs in explaining the association between past trauma exposure and distress in humanitarian settings in Jordan and Nepal. Br J Psychiatry 2012; 201: 276-81.

12 Mels C, Derluyn I, Broekaert E, Rosseel Y. The psychological impact of forced displacement and related risk factors on Eastern Congolese adolescents affected by war. J Child Psychol Psychiatry 2010; 51: 1096-104.

13 Betancourt TS, McBain R, Newnham EA, Brennan RT. Trajectories of internalizing problems in war-affected Sierra Leonean youth: examining conflict and postconflict factors. Child Dev 2012; 84: 455-70.

14 World Health Organization. Process of Translation and Adaptation of Instruments. WHO, 2013 (http://www.who.int/substance_abuse/ research_tools/translation/en/index.html).

15 Betancourt TS, Brennan RT, Rubin-Smith J, Fitzmaurice G, Gilman S. Sierra Leone's former child soldiers: a longitudinal study of risk, protective factors and mental health. J Am Acad Child Adolesc Psychiatry 2010; 49: 606-15.

16 Macksoud M, Aber J. The war experiences and psychosocial development of children in Lebanon. Child Dev 1996; 67: 70-88.

17 Layne CM, Olsen JA, Baker A, Legerski JP, Isakson B, Păsalić A. Unpacking trauma exposure risk factors and differential pathways of influence: Predicting post-war mental distress in Bosnian adolescents. Child Devel 2010; 81: 1053-76.

18 Pynoos R, Rodriguez N, Steinberg A, Stauber M, Frederick C. UCLA PTSD Index for DSM-IV (Revision 1). UCLA Trauma Psychiatry Program, 1998.

19 Layne CM, Olsen J, Baker A, Legerski J, Isakson B, Pasalic A. Unpacking trauma exposure risk factors and differential pathways of influence: predicting post-war mental distress in Bosnian adolescents. Child Dev 2010; 81: 1053-76.

20 Lavik N, Hauff E, Solberg O, Laake P. The use of self-reports in psychiatric studies of traumatized refugees: validation and analysis of HSCL-25. Nordic J Psychiat 1999; 53: 17-20.

21 Scholte $W$, Olff $M$, Ventevogel $P$, de Vries $C$, Jansveld $E$, Cardozo $B$, et al. Mental health symptoms following war and repression in Eastern Afghanistan. JAMA 2004; 292: 585-93.

22 UNICEF. Sierra Leone: Multiple Indicator Cluster Survey 2005. UNICE, 2007

23 Song S, Shaheen M. Assessing the impact of violence and war on youth in low- and middle-income countries. Child Youth Care Forum 2013; 42: 275-83.

24 Annan J, Green EP, Brier M. Promoting recovery after war in Northern Uganda: reducing daily stressors by allieviating poverty. J Aggression Maltreat Trauma 2013; 22: 849-68.

25 Rasmussen A, Nguyen L, Wilkinson J, Vundla S, Raghavan S, Miller KE, et al. Rates and impact of trauma and current stressors among Darfuri refugees in Eastern Chad. Am J Orthopsych 2010; 80: 227-36.

26 Miller KE, Omidian P, Rasmussen A, Yaquibi A, Daudzai H, Nasiri M. Daily stressors, war experiences, and mental health in Afghanistan. Transcult Psychiatry 2008; 45: 611-39.

27 Panter-Brick C, Eggerman M, Mojadidi A, McDade T. Social stressors, mental health and physiological stress in an urban elite of young Afghans in Kabul. Am J Hum Biol 2008; 20: 627-41.

28 Miller KE, Weine S, Ramic A, Brkic N, Bjedic Z, Smajkic A, et al. The relative contribution of war experiences and exile-related stressors to levels of psychological distress among Bosnian refugees. J Trauma Stress 2002; 15: 377-87.

29 Rasmussen A, Annan J. Predicting stress related to basic needs and safety in Darfur refugee camps: a structural and social ecological analysis. J Refugee Studies 2009; 23: 23-40. 
30 Lustig S, Kia-Keating M, Knight W, Geltman P, Ellis H, Kinzie JD, et al. Review of child and adolescent refugee mental health. J Am Acad Child Adolesc Psychiatry 2004; 43: 24-36.

31 Howard M, Hodes M. Psychopathology, adversity, and service utilization of young refugees. J Am Acad Child Adolesc Psychiatry 2000; 39: 368-77.

32 Fazel M, Reed RV, Panter-Brick C, Stein A. Mental health of displaced and refugee children resettled in high-income countries: risk and protective factors. Lancet 2012; 379: 266-82.

33 Neuner F. Assisting war-torn populations - Should we prioritize reducing daily stressors to improve mental health? Comment on Miller and Rasmussen (2010). Soc Sci Med 2010; 71: 1381-4.

34 Lund C, Breen A, Flisher AJ, Kakuma R, Corrigall J, Joska JA, et al. Poverty and common mental disorders in low and middle income countries: A systematic review. Soc Sci Med 2010; 71: 517-28.

35 Betancourt TS, Newnham EA, Hann K, McBain R, Akinsulure-Smith A Weisz J, et al. Addressing the consequences of violence and adversity: the development of a group mental health intervention for war-affected youth in Sierra Leone. In From Research to Practice in Child and Adolescent
Mental Health (eds J Raynaud, S Gau and M Hodes). Rowman \& Littlefield Publishers, 2014.

36 Annan J, Brier $M$. The risk of return: intimate partner violence in Northern Uganda's armed conflict. Soc Sci Med 2010; 70: 152-9.

37 Brewin C, Andrews B, Gotlib I. Psychopathology and early experience: a reappraisal of retrospective reports. Psychol Bull 1993; 113: 82-98.

38 Bolton P, Bass J, Betancourt TS, Speelman L, Onyango G, Clougherty K, et al. Interventions for depression symptoms among adolescent survivors of war and displacement in Northern Uganda: A randomized controlled trial. JAMA 2007: 298: 519-27.

39 Ruf M, Schauer M, Neuner F, Catani C, Schauer E, Elbert T. Narrative exposure therapy for 7- to 16-year olds: a randomized controlled trial with traumatized refugee children. I Trauma Stress 2010; 23: 437-45.

40 Tol WA, Barbui C, Galappatti A, Silove D, Betancourt TS, Souza R, et al. Mental health and psychosocial support in humanitarian settings: linking practice and research. Lancet 2011; 378: 1581-91.

Extra

\section{Clare Wadlow}

I am a room. Just a room. Nothing peculiar about me. Well, I don't think that I am special. Though you might say that my walls are dull and my paint is peeling a little, yes. You may comment that I don't seem very cosy. I imagine you think me rather sparse. You might point out that I haven't a curtain rail or a bar in my wardrobe to hang a hanger. My coat hooks are rather unusual and I seem to have mislaid my bathroom plug. Yet I am proud of my en suite wet room, well wouldn't you be? I have a big window, though it doesn't open very far. Look, I have a box of tissues and another of chocolates. There is a picture on the wall. That blu tack might make my paint a little worse but I think it's worth the risk.

She put it up the day before yesterday. I think she's doing better. The first painting never quite made the wall but I saw it on the floor, beneath the bed. It was dark and foreboding. This one seems more hopeful, maybe it's the sunrise, perhaps the glint of gold in the green on the trees. She laughed this morning. I heard it, I'm sure I did. Short and abrupt, but sweet. I was proud of her. The radio was on and someone made a joke, she must have been listening today. She must have been able to hear it.

I am filling up with objects now, at first she was barely here. I didn't know whether she would come back, she left nothing behind. Hardly a dent in the bed sheets. But now you can see it all, the two well-fingered books, the jumpers, a hairbrush and a bottle of moisturiser. The radio was the most recent addition. I am beginning to feel homely, purposeful, glad.

I don't like to think of our first few days together. I know I should be used to these things by now but I never know what to do. She cried of course. Not sobbing or screaming. It was a quiet cry, an exhausted, soft and unending echo which I bounced about my walls hoping someone would hear and come to help. But I couldn't make it loud enough. Sometimes she slept, but not for long. I tried to be calm, quiet, warm and dark; but nothing helped. She tossed and turned and wept again. I felt her deep desolation and I wanted to comfort her but I couldn't, no one could.

It's often like this. I am just a room but I have a big job, a heavy job. I'm glad there are others to help. I don't understand everything, but I've seen most of it here. Things always change eventually, somehow. I want to write on my walls in big yellow letters 'this too shall pass'. I want to tell them that I know life can become dark, confused and twisted. But that it can uncurl and the sun can come out again. There is calmness inside all of us I think. Somewhere. I am just a room, but this I know. 